\begin{tabular}{|c|c|}
\hline \multirow{3}{*}{ 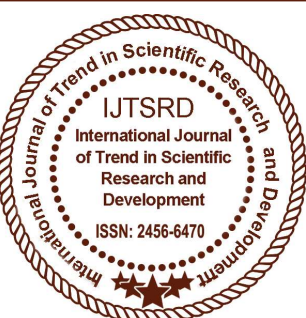 } & $\begin{array}{l}\text { International Journal of Trend in Scientific } \\
\text { Research and Development (IJTSRD) }\end{array}$ \\
\hline & International Open Access Journal \\
\hline & ISSN No: 2456 - 6470 | www.ijtsrd.com | Volume - 2 | Issue -3 \\
\hline
\end{tabular}

\title{
A Study of Emotional maturity among Urban and Rural College Going Students
}

\author{
Dr. Ramesh D. Waghmare \\ Assistant Professor, Godawari College Ambad, Jalna, Maharashtra, India
}

\begin{abstract}
Emotional Maturity is a natural and inevitable essential outcome of student growth and development. The Emotional maturity becomes important in the behavior of individuals. As the students are the pillars of the future generations, their value pattern of Emotional Maturity are vital. The purpose research attempted to study the Gender Difference on Emotional maturity. To study by research seared variables in Gender and Emotional maturity sub factor. The sample has 80 college students in 40 were Urban (20 Male and 20 Female) College Students and 40 Rural (20 Male and 20 Female) College Students. The scale was used for data collection Emotional Maturity Scale by Singh and Bhargava (1990). Factorial design was used and data were analysis by Mean, SD and 'F' values. Results show that Urban Students high Emotional Unstability, high Emotional regression, high Social maladjustment, high Personality disintegration, high Lack of independence and high Emotional maturity than Rural Students.
\end{abstract}

Keyword: Faculty, Emotional Unstability, Emotional Regression, Social Maladjustment, Personality Disintegration, Lack of Independence, Emotional maturity

\section{INTRODUTION}

The tern emotional maturity has been described by experts in many ways-typically as the effective determinate of personality pattern. Second, it also helps us to control the growth of adolescent's development. From a scientific point of view personality is the organization of some traits and emotional maturity is one of them.

The process of maturity emotionally is never complete, for a person in fairly good health mentally continues to grow more "mauler" in his attitude toward life and toward himself as long as he lives. Therefore, when we say that a major aim of a good educational program is to help learners to gain in emotional maturity, what we means is not the achievement of a certain and product that can be graded or rated on graduation day. But rather seeking to help the child in a process of development that continues long after most people leave school.

Emotional maturity that is in keeping with the facts of development and the potentialities involved in the process of development must stress not simply restriction and control but also the positive possibilities inherent in human nature. According to this view, emotional maturity involves the kind of living that most richly and fully expresses what a person has in him at any level of his development.

Emotional maturity constitutes evaluating emotions of oneself and others, identifying and expressing feelings, balancing state of heart and mind, adoptability and flexibility, appreciating' Others' point of view, helping others, delaying gratification of immediate psychological satisfaction".

Emotional maturity according to Walter D. Smiston (1974) is a process through which the personality continuously strives for greater sense of emotional health, both intro-physically and intropersonality. 


\section{Review of literature:-}

Jitender and Mona, (2015) indicated that there is significant difference of emotional maturity among college students on the basis of locality. Nelson (2000) and Singh (2002) found reported significant difference in emotional competence of urban and rural students in respect of their emotional maturity. Kaur, H. (2004) this study reported significant differences in the emotional maturity of Adolescents of rural and urban areas. Tribhovan B. Makwana, (2015) indicated that There is significance difference between emotional maturity among rural and urban under graduate students. Singh, Rashee (2012)- “A Comparative Study of Rural and Urban Senior Secondary School Students in Relation to Emotional Maturity" studied for research paper and found that 1 . No significant difference was found between rural and urban senior secondary school students in relation to emotional maturity. 2. No significant difference was found between rural male and rural female senior secondary school students in relation to emotional maturity. 3. No significant difference was found between urban male and urban female senior secondary school students in relation to emotional maturity.

\section{Statement of the problem}

"A Study of Emotional maturity among Urban and Rural College Going Students"

\section{Objectives}

To examine the Emotional maturity among Urban and Rural College Students.

\section{Hypotheses}

"There is no significant difference between Urban and Rural College Students college students with Emotional maturity dimension on Emotional Unstability, Emotional Regression, Social Maladjustment, Personality Disintegration, and Lack of Independence.

\section{Methods}

\section{Participants}

The present study sample go was selected from college students of Ambad City Jalna Dist. in Maharashtra. To select the sample Gender in which students study of College Students were considered as per independent variable taken in this research stratified random sampling method was employed to select the unit of sample. Total sample of present study 80 college students, in which 40 were Urban (20 Male and 20 Female) College Students and 40 Rural (20 Male and 20 Female) College Students. The subject selected in this sample will be used in the age group of 18 years to 21 years (Mean - 19.16, SD2.01.) and Ratio 1:1.

\section{Research Design}

2 X 2 factorial design used in the present study.

\section{Variables of the Study}

\begin{tabular}{|c|c|c|c|}
\hline Variable & $\begin{array}{l}\text { Type of } \\
\text { variable }\end{array}$ & $\begin{array}{l}\text { Sub. } \\
\text { variable }\end{array}$ & $\begin{array}{l}\text { Name } \\
\text { variable }\end{array}$ \\
\hline Gender & Independent & 02 & $\begin{array}{l}\text { 1) Urban 2) } \\
\text { Rural }\end{array}$ \\
\hline Scient & Dependent & 05 & $\begin{array}{l}\text { 1) Emotional } \\
\text { Unstability } \\
\text { 2) Emotional } \\
\text { regression } \\
\text { 3) Social } \\
\text { maladjustment } \\
\text { 4) Personality } \\
\text { disintegration } \\
\text { 5) Lack of } \\
\text { independence }\end{array}$ \\
\hline
\end{tabular}

\section{Instruments}

\begin{tabular}{|l|l|l|}
\hline \multicolumn{1}{|c|}{ Aspect } & Name of the Test & \multicolumn{2}{|c|}{ Author } \\
\hline Emotional & Emotional & Dr. Yashvir \\
maturity & Maturity Scale & Singh \\
& $(1990)$ & Dr. Mahesh \\
& & Bhargava \\
\hline
\end{tabular}

\section{Emotional Maturity Scale:}

Emotional Maturity Scale is constructed and standardized by Singh and Bhargava (1990). The scale comprised of 48 items and is based on five major areas of emotional maturity i.e. emotional unstability, emotional regression, social maladjustment, personality disintegration and lack of independence. The highest the score on the scale is greater the degree of the emotional immaturity and vice-versa. It is a self -reporting five point scale. Items of the scale are in question form demanding information for each in any of the five options- 'very much', 'much', 'undecided', 'probably', 'never'. The highest score of the Emotional Maturity Scale can be obtained 240 and lowest can be 48 . The test-retest 
reliability of the scale was 0.75 and internal consistency of the scale was checked by calculating the coefficient of correlations

between total scores and scores on each of the five areas i.e. emotional unstability (.75), emotional regression (.63), social maladjustment (.58), personality disintegration (.86), lack of independence (.42). The scale was validated against external criteria i.e. the Gha (.64). This scale is meant for adolescents and adults.

\section{Procedures of data collection}

The following research methodology was used in the present study. The primary information was gathered by giving personal information from to each to each student. The students were called in a small group of 10 to 15 students. To fill the inventories subjects were given general instructions belongs to each scale. The students provided the Emotional maturity Scale.

\section{Data analysis}

The data were analyzed as follows.

The Mean and SD with graphical representation for Gender (Male and Female College Students) on Emotional maturity was analyzed. A simple design was selected to adequate of statistical analysis of ANOVA in order to examine the roll of main as well as subsequently on student's Emotional maturity.

\section{Results and Discussion}

The analysis of data interpretation and discussion of the results are presented below.

Table No.01 Show the mean, SD and F value of Gender on Emotional Unstability

\begin{tabular}{|l|l|l|l|l|l|l|l|}
\hline Gender & Mean & SD & N & DF & Mean Difference & F & Sign \\
\hline Urban Students & 29.62 & 4.88 & 40 & 78 & 3.05 & 6.80 & 0.05 \\
Rural Students & 26.57 & 5.67 & 40 & & & & \\
\hline
\end{tabular}
(Critical value of "f" with df 79 at $0.05=3.96$ and at $0.01=6.96$, NS= Not Significance)

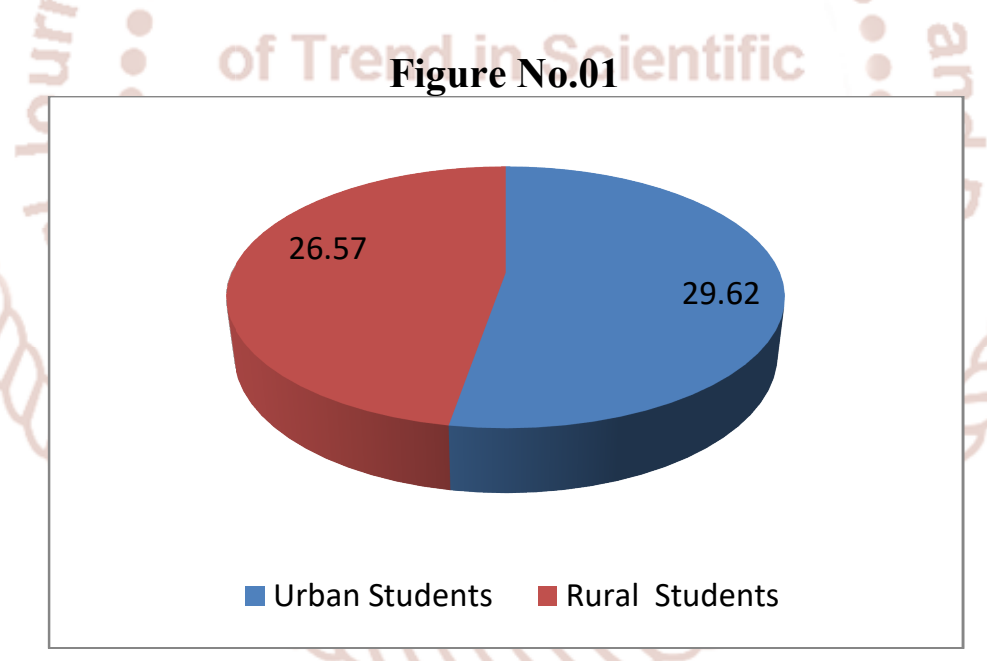

Observation of the table No.01and Figure No.01 indicated that the mean value of two classified group seems to differ from each other on Emotional Unstability. The mean and SD value obtained by the Urban college students 29.62, SD 4.88 and Rural College students was 26.57, SD 5.67, but on the basis of mean observation it would that mean difference 3.05. Both group ' $F$ ' ratio was 6.80 at a glance those Urban college student shows high score than Rural college students.

In the present study was hypothesis related Emotional Unstability and Gender. It was "There is no significant difference between Urban and Rural college students on Emotional Unstability. Gender effect represent the Emotional Unstability was significant (F- 6.80, 1 and 79, P- 0.05). This is significant 0.05 levels because they obtained ' $F$ ' value are high than table values at 0.05 . In the present study was found that Urban and Rural college students differ from Emotional Unstability. The findings of the not supported the hypothesis, they are this hypothesis rejected the present study. Its means that Urban Students high Emotional Unstability than Rural Students. 
International Journal of Trend in Scientific Research and Development (IJTSRD) ISSN: 2456-6470

Table No.02 Show the mean, SD and F value of Gender on Emotional regression

\begin{tabular}{|l|l|l|l|l|l|l|l|}
\hline Gender & Mean & SD & N & DF & Mean Difference & F & Sign \\
\hline Urban Students & 26.72 & 5.79 & 40 & \multirow{2}{*}{7.65} & 4.97 & 0.05 \\
\cline { 1 - 5 } Rural Students & 24.07 & 5.07 & 40 & 78 & & & \\
\hline
\end{tabular}

(Critical value of "f" with df 79 at $0.05=3.96$ and at $0.01=6.96$, NS $=$ Not Significance)

Figure No.02

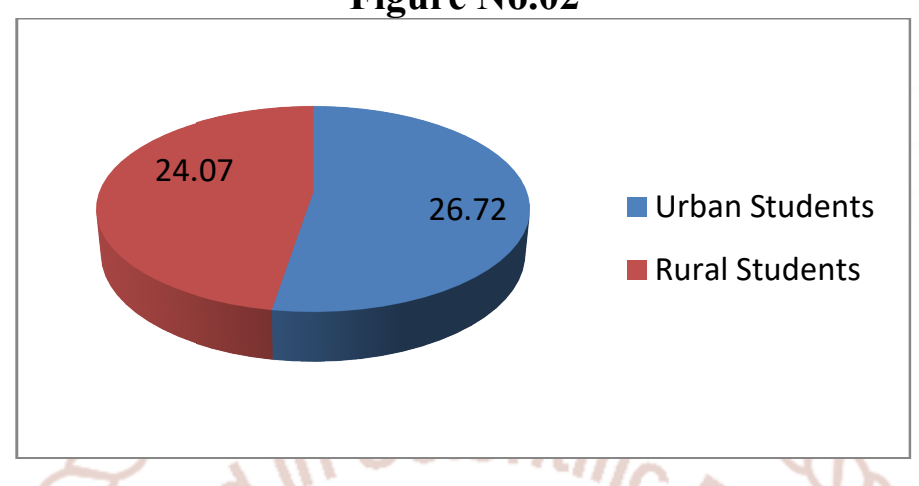

Observation of the table No.02and Figure No.02 indicated that the mean value of two classified group seems to differ from each other on Emotional regression. The mean and SD value obtained by the Urban college students 26.72, SD 5.79 and Rural College students was 24.07, SD 5.07, but on the basis of mean observation it would that mean difference 2.65. Both group ' $F$ ' ratio was 4.97 at a glance those Urban college student shows high score than Rural college students.

In the present study was hypothesis related Emotional regression and Gender. It was "There is no significant difference between Urban and Rural college students on demotion Emotional regression. Gender effect represent the Emotional regression was significant (F- 4.97, 1and 79, P- 0.05). This is significant 0.05 levels because they obtained ' $F$ ' value are high than table values at 0.05 . In the present study was found that Urban and Rural college students differ from Emotional regression. The findings of the not supported the hypothesis, they are hypothesis rejected the present study. Its means that Urban College Students high Emotional regression than Rural College Students.

Table No.03 Show the mean, SD and F value of Gender on Social maladjustment

\begin{tabular}{|l|l|l|l|l|l|l|l|}
\hline Gender & Mean & SD & N & DF & Mean Difference & F & Sign \\
\hline Urban Students & 25.97 & 5.79 & 40 & & 4.12 & 10.47 & 0.01 \\
\hline Rural Students & 21.85 & 5.87 & 40 & 78 & & & \\
\hline
\end{tabular}

(Critical value of "f" with df 79 at $0.05=3.96$ and at $0.01=6.96, \mathrm{NS}=$ Not Significance)

Figure No.03

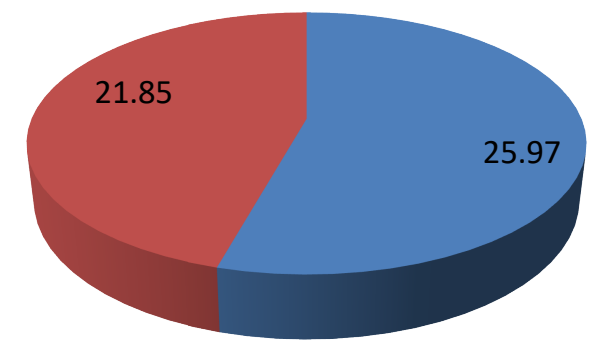

Urban Students

Rural Students

Observation of the table No.03 and Figure No.03 indicated that the mean value of two classified group seems to differ from each other on Social maladjustment. The mean and SD value obtained by the Urban college 
students 25.97, SD 5.79 and Rural College students was 21.85, SD 5.87, but on the basis of mean observation it would that mean difference 4.12. Both group ' $F$ ' ratio was 10.47 at a glance those Urban college student shows high score than Rural college students.

In the present study was hypothesis related Social maladjustment and Gender. It was "There is no significant difference between Urban and Rural college students on demotion Social maladjustment. Gender effect represent the Satisfaction was significant (F- 4.12, 1and 79, P- 0.01 and 0.05 ). This is significant 0.01 and 0.05 levels because they obtained ' $F$ ' value are high than table values at 0.01 and 0.05 . In the present study was found that Urban and Rural college students differ from Social maladjustment. The findings of the not supported the hypothesis, they are hypothesis rejected the present study. Its means that Urban College Students high Social maladjustment than Rural College Students.

Table No.04 Show the mean, SD and F value of Gender on Personality disintegration

\begin{tabular}{|l|l|l|l|l|l|l|l|}
\hline Gender & Mean & SD & N & DF & Mean Difference & F & Sign \\
\hline Urban Students & 25.07 & 8.17 & 40 & & 5.95 & 15.18 & 0.01 \\
\hline Rural Students & 19.12 & 5.42 & 40 & 78 & & & \\
\hline
\end{tabular}

(Critical value of "f" with df 79 at $0.05=3.96$ and at $0.01=6.96, \mathrm{NS}=$ Not Significance)

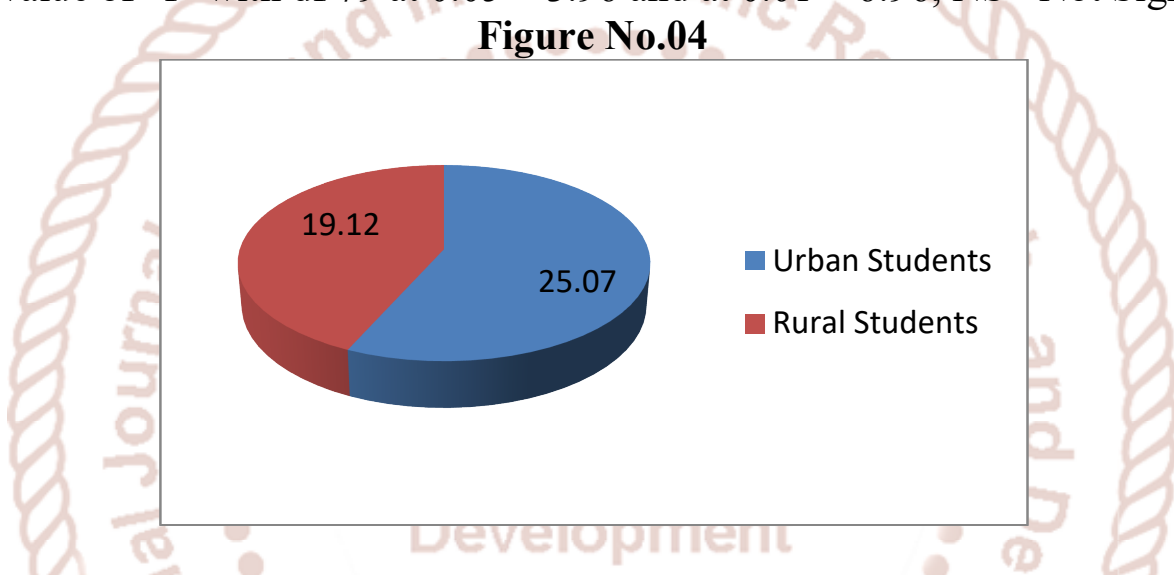

Observation of the table No.04 and Figure No.04 indicated that the mean value of two classified group seems to differ from each other on Personality disintegration. The mean and SD value obtained by the Urban college students 25.07, SD 8.17 and Rural College students was 19.12, SD 5.42, but on the basis of mean observation it would that mean difference 5.95 . Both group ' $F$ ' ratio was 15.18 at a glance those Urban college student shows high score than Rural college students.

In the present study was hypothesis related Personality disintegration and Gender. It was "There is no significant difference between Urban and Rural college students on demotion Personality disintegration. Gender effect represent the Personality disintegration was significant (F- 15.18, 1and 79, P- 0.01 and 0.05). This is significant 0.01 and 0.05 levels because they obtained ' $F$ ' value are high than table values at 0.01 and 0.05. In the present study was found that Urban and Rural college students differ from Personality disintegration. The findings of the not supported the hypothesis, they are hypothesis rejected the present study. Its means that Urban College Students high Personality disintegration than Rural College Students.

Table No.05 Show the mean, SD and F value of Gender on Lack of independence

\begin{tabular}{|l|l|l|l|l|l|l|l|}
\hline Gender & Mean & SD & N & DF & Mean Difference & F & Sign \\
\cline { 1 - 5 } Urban Students & 21.35 & 6.04 & 40 & \multirow{2}{*}{7.1} & 3.1 & 7.00 & 0.01 \\
\cline { 1 - 5 } Rural Students & 18.25 & 4.80 & 40 & & & & \\
\hline
\end{tabular}

(Critical value of "f" with df 79 at $0.05=3.96$ and at $0.01=6.96, \mathrm{NS}=$ Not Significance) 
Figure No.05

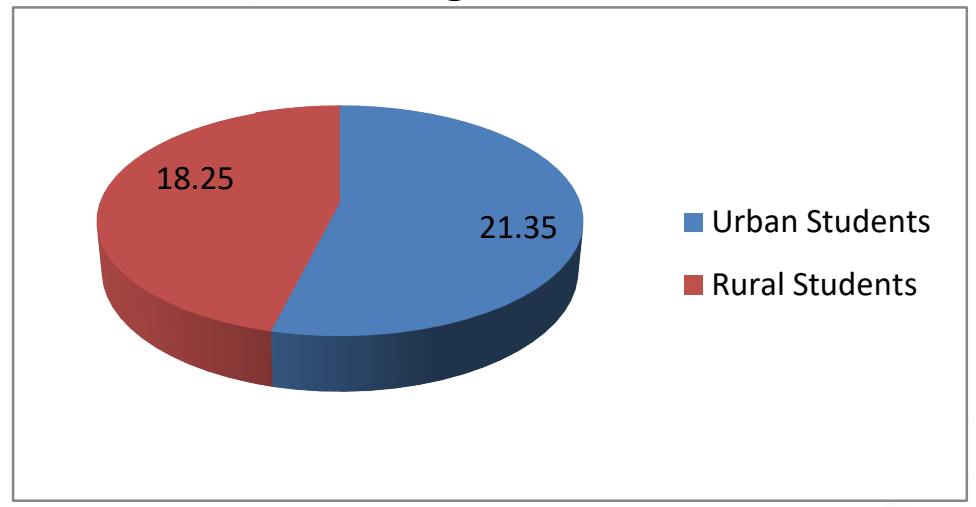

Observation of the table No.05 and Figure No.05 indicated that the mean value of two classified group seems to differ from each other on Lack of independence. The mean and SD value obtained by the Urban college students 21.35, SD 6.04 and Rural College students was 18.25, SD 4.80, but on the basis of mean observation it would that mean difference 3.1. Both group ' $F$ ' ratio was 7.00 at a glance those Urban college student shows high score than Rural college students.

In the present study was hypothesis related Lack of independence and Gender. It was "There is no significant difference between Urban and Rural college students on demotion Lack of independence. Gender effect represent the Lack of independence was significant ( F- 7.00, 1and 99, P- 0.01 and 0.05). This is significant 0.01 and 0.05 levels because they obtained ' $F$ ' value are high than table values at 0.01 and 0.05 . In the present study was found that Urban and Rural college students differ from Lack of independence. The findings of the not supported the hypothesis, they are hypothesis rejected the present study. Its means that Urban College Students high Lack of independence than Rural College Students.

Table No.06 Show the mean, SD and F value of Gender on Emotional maturity

\begin{tabular}{|l|l|l|l|l|l|l|l|}
\hline Gender & Mean & SD & N & DF & Mean Difference & F & Sign \\
\hline Urban Students & 130.50 & 25.88 & 40 & & 20.6 & 17.56 & 0.01 \\
\cline { 1 - 4 } & 109.40 & 21.34 & 40 & 78 & & & \\
\hline
\end{tabular}

(Critical value of "f" with df 79 at $0.05=3.96$ and at $0.01=6.96, \mathrm{NS}=$ Not Significance)

Figure No.06

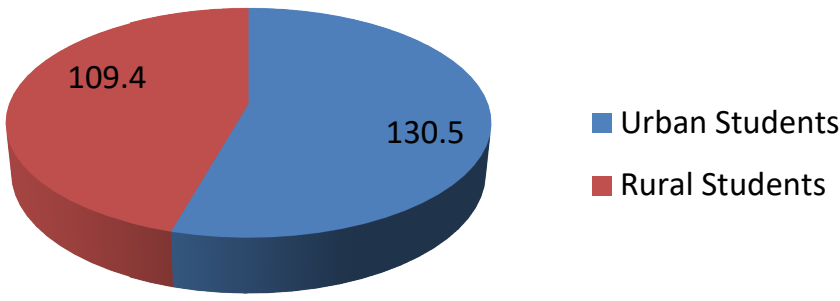

Observation of the table No.01 and Figure No.06 indicated that the mean value of two classified group seems to differ from each other on Emotional maturity. The mean and SD value obtained by the Urban college students 130.50, SD 25.88 and Rural College students was 109.40, SD 21.34, but on the basis of mean observation it would that mean difference 20.6. Both group ' $F$ ' ratio was 17.56 at a glance those Urban college student shows high score than Rural college students.

In the present study was hypothesis related Emotional maturity and Gender. It was "There is no significant difference between Male and Female college students on demotion Emotional maturity. Gender effect represent the Emotional maturity was not significant 
((F- 17.56, 1and 79, P- 0.01 and 0.05). This is significant 0.01 and 0.05 levels because they obtained ' $F$ ' value are high than table values at 0.01 and 0.05 . In the present study was found that Urban and Rural college students differ from Emotional maturity. The findings of the not supported the hypothesis, they are hypothesis rejected the present study. Its means that Urban College Students high Emotional maturity than Rural College Students.

A similar finding was found that Sinha (2014) found that boys have better emotional maturity than their girls. An Opposite finding was found that Kumar (2014), Singh, Rashee (2012), Kaur, H. (2004) in her study found No significant difference was found in emotional maturity of boys and girls.

\section{Delimitations of the study}

1) The finding of the study is based on very sample.

2) The sample was restricted to Jalna Dist. in Maharashrta.

3) The study was restricted to only B.A. arts college students (arts facility) only.

4) The study was restricted students are only 18-21 years only.

\section{Conclusions:}

1) Urban Students high Emotional Unstability than Rural Students.

2) Urban College Students high Emotional regression than Rural College Students.

3) Urban College Students high Social maladjustment than Rural College Students.

4) Urban College Students high Personality disintegration than Rural College Students.

5) Urban College Students high Lack of independence than Rural College Students.

6) Urban College Students high Emotional maturity than Rural College Students.

\section{REFERENCES}

1) Aleem, S.(2005). Emotional Stability among College Youth, Journal of the Indian Academy of Applied Psychology, 31(1-2), 100-102.

2) Anand, A.K., Kunwar, N. and Kumar, A.(2014).Impact of Different Factors on Emotional Maturity of Adolescents of CoedSchool. International, Research Journal of Social Sciences, 3(11), 17-19.
3) Bal, B.S. and Singh, D.(2015).An Analysis of the Components of Emotional Maturity and Adjustment in Combat Sport Athletes. American Journal of Applied Psychology, 4(1), 13-20.

4) Balakrishnan, V.(2013).Emotional Maturity of Teachers in Relation to Caste and Religion. International Journal of Teacher Educational Research, 2(6), 8-17.

5) Bhagyashri Aashra, and Yogesh A. Jogsan, (2013) Emotional Maturity And Self-Actualization In Graduate And Post-Graduate Students; Journal of Research in Humanities and Social Science, Volume1 Issue 4, pp: 15-18

6) Bhanwer, M. K.(2012).Emotional Maturity Patterns of Adolescents as Determined by Gender Differences. Research Analysis and Evaluation, III (35), 61-63. disruptive behaviors in general education classrooms. Journal of Emotional and Behavioral Disorders, 8(1), 27-37.

7) Gunde Rajendraand Parit , (2015) Effect of Gender and Faculty on Emotional Maturity of College Students; The International Journal of Indian Psychology, Volume 2, Issue 3,35-43.

8) Jitender and Mona, (2015) emotional maturity and anxiety among college students in relation to demographic variables: a study; bhartiyam international journal of education \& research, Volume 4, Issue II,8-20.

9) Kaur, B. (2004). Effect of Emotional quotient and intelligence quotient on achievement of $9^{\text {th }}$ class students. Unpublished M.Ed. dissertation , Panjab University, Chandigarh.

10) Kumar, S.(2014).Emotional Maturity of Adolescent Students in Relation to Their Family Relationship. International Research Journal of Social Sciences, 3(3), 6-8.

11) Manoharan, R. John Louis and I. Christie Doss (2007)- "Emotional Maturity of Post-Graduate Students in Pondicherry Region", experiments in education, New Delhi, Vol.35 No.8.

12) Misra, S. (2009).Emotional Maturity and Adjustment level of College Students, PsychoLingua, 39(2), 114-116.

13) Mukesh kumar panth, nandani chaurasia, and mansi gupta, (2015) a comparative study of adjustment and emotional maturity between gender and stream of undergraduate student; International Journal of Research in Social 
Sciences And Humanities, Vol. No. 5, Issue No. III, 1-12.

14) Nelson, J. R., \& Roberts, M. L. (2000). Ongoing reciprocal teacher student interactions involving

15) Sharma, N.,(2012).Role of gender and various personal and familial variables in emotional maturity of adolescents. Golden Research Thoughts, 1(7),7-9.

16) Singh, R., Pant, K. and Valentina, L.(2013).Gender on Social and Emotional Maturity of Senior School Adolescents: A Case Study of Pantnagar. Stud Home Com Sci, 7(1), 16.

17) Singh, Rashee (2012)- "A Comparative Study of Rural and Urban Senior Secondary School Students in Relation to Emotional Maturity", International Indexed \&Referred Research Journal, VoL.III, ISSUE-32 pp-34-35

18) Singh, Y. \& Bhargava, M. (1999). Manual for Emotional Maturity Scale (EMS). Agra: National Psychological Corporation.

19) Singh, Y. and Bhargava, M. (1990).Manual for Emotional Maturity scale. Agra:-T National Psychological Corporation.
20) Sinha, V. K.(2014).A Study of Emotional Maturity and Adjustment of College Student. Indian Journal of Applied Research, 4(5), 594-595.

21) Subbarauan, K. And Veliappan, A.(2013).A Study on Emotional Maturity of High School Students. Indian Journal of Applied Research, 3(11), 142143.

22) Subbarauan, K. and Visvanathan, G.(2011).A study on emotional maturity of college students. Recent Research in Science and Technology, 3, 153-155.

23) Tribhovan B. Makwana, (2015) A Comparative Study of Emotional Maturity among Girls and Boys under Graduate Student; The International Journal of Indian Psychology, Volume 2, Issue 2, 53-57.

24) Wani, M.A. and Masih, A.(2015).Emotional Maturity across Gender and Level of Education. The International Journal of Indian Psychology, 2(2), 63-72.

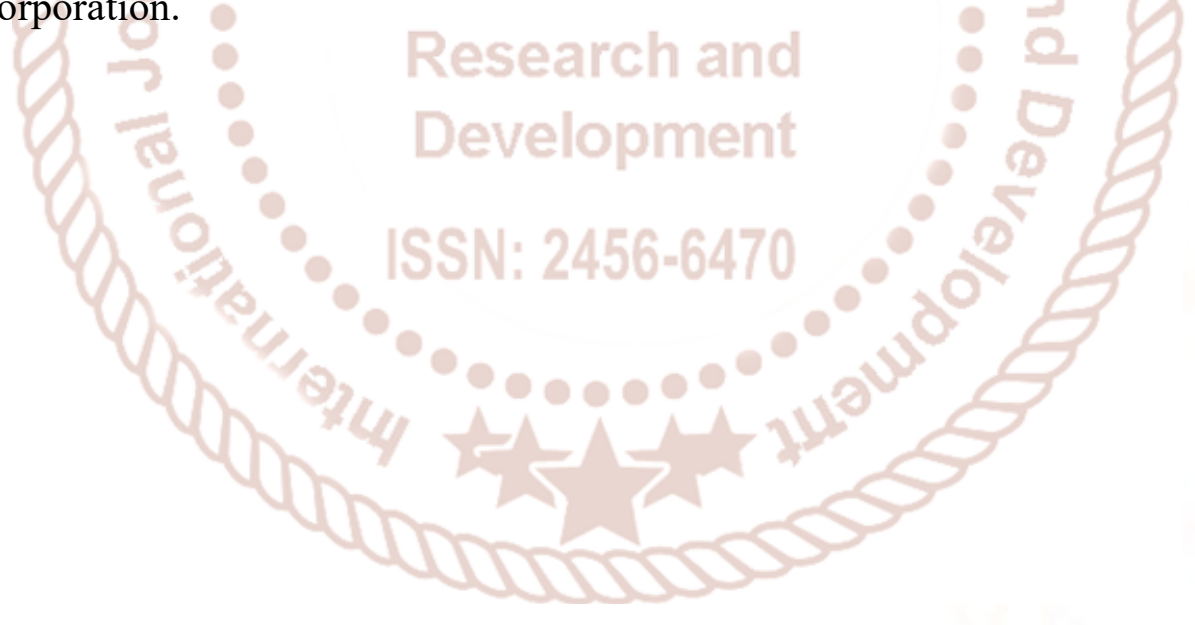

